\title{
Screen-printable electrochromic polymer inks and ion gel electrolytes for the design of low-power, flexible electrochromic devices
}

\author{
Sara Santiago[a], Miguel Aller[b], F. Javier del Campo [b], and Gonzalo Guirado*[a]
}

[a] Department de Química, Universitat Autònoma de Barcelona, C/ Til·lers s/n, 08193Cerdanyola del Vallés, Barcelona, Spain.

[b] Instituto de Microelectrónica de Barcelona, IMB-CNM-CSIC; Campus Universitat Autònoma de Barcelona, C/ Til.lers s/n, 08193-Cerdanyola del Vallés, Barcelona, Spain.

E-mail: gonzalo.guirado@uab.cat

\begin{abstract}
We have developed electrochromic inks and electrolyte materials to enable mass production of flexible electrochromic displays (ECDs) and other optoelectronic devices by screen printing. Here we present a new screen-printable ink incorporating electrochromic polymer, poly(3,4-propylenedioxythiophene)bis(ethylhexyloxy), referred to here as ECP-Magenta, and antimony-doped tin oxide $\left(\mathrm{ATO} / \mathrm{TiO}_{2}\right)$ particles to facilitate electron transport. Their dispersion in a $\mathrm{P}(\mathrm{VDF}-\mathrm{co}-\mathrm{HFP})$ binder leads to the formation of a new electrochromic ink that is suitable for screen printing. This strategy opens the door to the preparation of similar electrochromic inks based on other organic or polymeric compounds. This approach is scalable and can applied to different fields. Ion gels (IGs) composed of $\mathrm{P}(\mathrm{VDF}-\mathrm{co}-\mathrm{HFP})$ and room temperature ionic liquids (RTILs) are promising solid-state electrolytes with high ionic conductivity, flexibility, elasticity and ecofriendliness. The electrochemical features of different ion gels were analyzed as a function of composition and nature of the ionic liquid. Hence, new formulations of IGs were developed, evaluated by Electrochemical Impedance Spectroscopy, Cyclic Voltammetry, before being incorporated into ECDs. The electrochromic performance of ECP-Magenta ink combined with the RTIL-based IG was evaluated by terms of spectroelectrochemistry showing that fully flexible ECD operating at voltages below $1 \mathrm{~V}$ can be screen-printed.
\end{abstract}

Keywords: Electrochromism • ECP-Magenta • Iongel • Screen-printing • 


\section{Introduction}

Electrochromic (EC) materials change colour upon the application of a current or voltage ${ }^{1}$ An increasing number of reports focuses on the development of electrochromic devices (ECD) such as display panels ${ }^{2}$, EC smart windows ${ }^{3,4}$ and sunglasses. ${ }^{5,6}$ There is a large number of electrochromic materials that can be classified into three main groups: inorganic metal oxides, small organic molecules and polymeric materials. It is important to note that usually voltages between 2 and $3 \mathrm{~V}$ are needed in order to reach full contrast in electrochromic devices. The use of high voltages requires caution with pulse lengths to avoid degradation. Hence the design of low-power devices, which can be switched over a useful range of optical transmissions using voltages lower than $1 \mathrm{~V}$ is highly desirable. In this work, we report an electrochromic device based on polymeric materials where the switching voltage is considerable smaller than that required by other solid-state EC devices reported to date. ${ }^{7-9}$

In this sense, conjugated polymers have been the subject of many studies in recent years as electrochromes as a result of the feasibility of customization of physico-chemical properties such as colour control through steric and electronic effects, solubility in common solvents, reversibility, rapid switching times, and high colour contrast ${ }^{10}$. Among conjugated polymer electrochromes, poly(3,4-alkylenedioxythiophenes) have gained significant attention as a result of their ability to switch between vibrantly coloured states and highly transmissive states in seconds or less, and their long-term switching stability. ${ }^{11}$ 12 Poly(3,4- propylenedioxythiophene) derivatives can be regiosymmetrically disubstituted on the propylene bridge with a range of functional groups to afford high solubility in common organic solvents while still maintaining exceptional switching properties. ${ }^{13,14}$ The electrochromic conducting material used in this work which, for convenience will be referred to as ECP-Magenta, belongs to this class (Figure 1). The polymer exhibits an intense and vibrant magenta colour in its as cast, neutral state and becomes transparent when it is oxidized. This results in a high colour contrast exceeding $60 \%{ }^{12,15}$ 


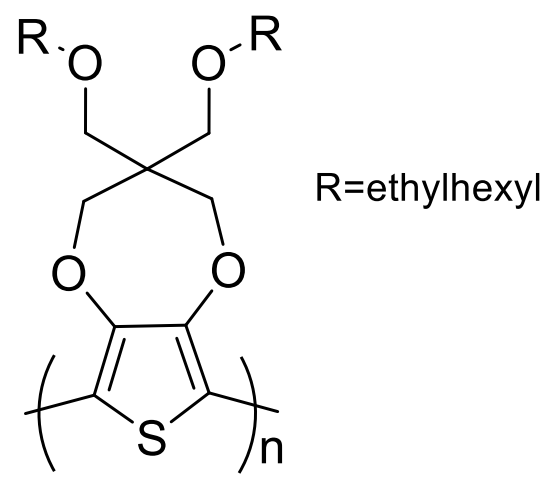

Neutral state

Figure 1. Molecular structure of ECP-Magenta polymer

The construction of solid and flexible systems is a key current trend in the area of electrochromic devices, but processes for their mass production are scarce and costly. 14,16-18 Moreover, despite the efforts made to prepare soluble conjugated polymers that facilitate their processing and the development of electrochromic applications, simultaneously achieving adequate color properties, high performance and good solubility remains a challenge. ${ }^{19,20}$ Besides, conjugated polymers can be synthetically modified to be highly soluble in a variety of organic solvents, but their rheologic properties are often unsuitable for coating techniques such as screen printing unless additives are used, which can adversely affect the electrochromism of the resulting coatings. Here we present a novel strategy to formulate screen-printable electrochromic inks, demonstrating this proof of concept using the conjugated polymer poly(3,4propylenedioxythiophene) (ECP-Magenta), which maintains the native electrochromic properties of the original ECP-Magenta polymer. Screen-printing enables the design and integration of each of the components of an electrochromic device in a streamlined and cost-effective process that can be adapted to a wide variety of substrates. This method has been widely used for the construction of printed and patterned conjugated polymers for solar cells and light-emitting diodes ${ }^{21-24}$. In line with previous reports ${ }^{25-29}$, we propose the use of carrier conductive metal oxide particles dispersed in a resin binder, with the novelty of incorporating the ECP-Magenta polymer as the electrochromic coating. We have investigated the use of antimony-doped tin oxide microparticles $\left(\mathrm{ATO} / \mathrm{TiO}_{2}\right)$ as a conducting light-coloured material for use in spectroelectrochemistry ${ }^{30}$. This allows not only to observe the colour change of the electrochromic compounds, but also it is a less expensive material than other typical metal oxides as indium-tin oxide nanoparticles 
(ITO-NP's) commonly used. Despite the electrochromism that ATO microparticles can show, in this case, due to the low potential at which ECP-Magenta is oxidized, the change in color of ATO microparticles does not occur.

In addition to the electrochromic polymer, the electrolyte is another key device component providing a source of ions for charge-balancing and current transport purposes. Polymeric gel electrolytes are promising electrolyte materials due to their low cost, non-volatility, and long term chemical stability ${ }^{31,32}$. However, only few gel electrolytes show sufficiently high ionic conductivity, in the order of $\mathrm{mS} \mathrm{cm}^{-1}$. Among the possible candidates that can be used for flexible ECD, some of the most promising are ion gels (IGs) ${ }^{33,34}$ since they show high conductivity and large electrochemical windows ${ }^{35}$. IGs are solid electrolytes composed of a copolymer and a room temperature ionic liquid (RTIL). RTILs have become the focus of many studies due to unique properties such as moderate ionic conductivity, non-toxicity, thermal stability up to $300^{\circ} \mathrm{C}$, electrochemical stability and low volatility. The resulting electrolytes exhibit suitable features for ECD fabrication such as: transparency, elasticity, flexibility and high ionic conductivity. IGs electrolytes can be cut and laminated on layers, but they can even be screen-printed. This enables a very easy, streamlined fabrication of ECDs where all components are flexible ${ }^{36-38}$.

In the present work, we have synthesized IGs based on P(VDF-co-HFP) with sufficiently high ionic conductivity to serve as electrolytes in ECDs. Although the use altogether of P(VDF-co-HFP) with imidazolium ionic liquids is well-known, as far as we are aware this time where a systematic study of IGs electrochemical properties is function of the IL nature and concentration is performed. P(VDF-co-HFP) has a high dielectric constant that helps ionic dissociation, and we have explored the influence of using one of the following ILs (1-ethyl-3-methylimidazolium bis(trifluoromethylsulfonyl)imide ([EMIM]][TFSI]), 1-butyl-3-methylimidazolium bis(trifluoromethylsulfonyl)imide ([BMIM]][TFSI]), 1-butyl-3-methylimidazolium hexafluorophosphate bis(trifluoromethylsulfonyl)imide ([BMIM][PF 6$]$ ), and 1-butyl-3-methylimidazolium tetrafluroborate ([BMIM]][BF4]) at different weight ratios (from 1:1 to 1:5) on their conductivity and electrochemical window.

Through the use of the screen printable electrochromic ink formulation developed here, and the choice of an appropriate ion gel, we demonstrate the construction of a fully screen-printed and flexible electrochromic device. We believe this process can be further adapted to a wide variety of comparable conjugated polymers for various other 
electrochemical devices, which not only provides an inexpensive and rapid fabrication route to produce highly customized ECD in the laboratory, but which can also be transferred to higher volume production environments.

\section{Results and Discussion}

\section{a) ECP-Magenta ink formulation and structural characterization}

A dispersion was formed by sonicating $6 \mathrm{~mL}$ of a $30 \mathrm{mg} / \mathrm{mL}$ solution of ECP-Magenta and $1 \mathrm{~g}$ of $\mathrm{ATO} / \mathrm{TiO}_{2}$ particles in dichloromethane $\left(\mathrm{CH}_{2} \mathrm{Cl}_{2}\right)$ for 15 minutes. The solvent was then allowed to evaporate at room temperature. The resulting solid (ECPMagenta@ATO/ $/ \mathrm{TiO}_{2}$ ) was ground into a fine powder and then dispersed in a resin binder consisting of $\mathrm{P}(\mathrm{VDF}-\mathrm{co}-\mathrm{HFP})$ polymer dissolved at $15 \%$ w.t in dimethylpropylurea (DMPU). The ECP-Magenta@ATO/TiO 2 -to-binder ratio was approximately 1:5. After thorough mixing, a smooth paste was obtained that had a suitable consistency to be used as ink for screen-printing with good elasticity and flexibility.

Figure 2 shows SEM images of stenciled films of ECP-Magenta ink. A homogeneous distribution of the ink components can be seen in Figure 2a. A closer look to the material reveals an amorphous and porous structure (Figure 2b). P(VDF-co-HFP) polymer leads to this porous morphology and facilitates ion diffusion through the electrochromic layer which may be related to the enhancement of its electrochromic properties-

a)

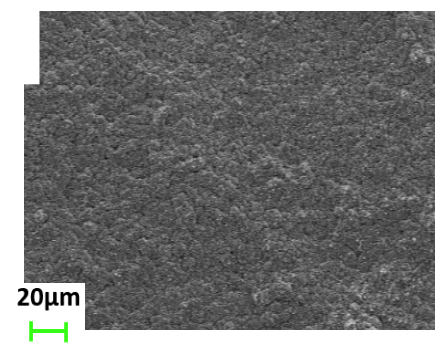

b)

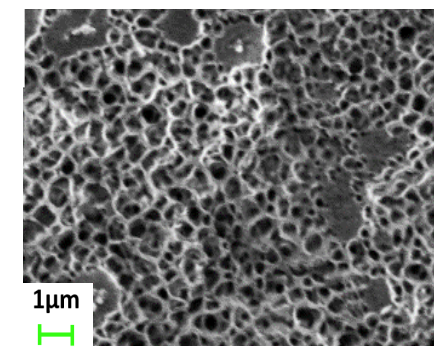

c)

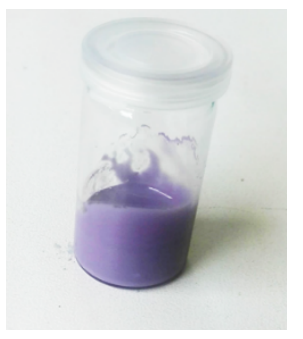

Figure 2. a) b) SEM images of ECP-Magenta ink films. c) Sample of ECP-Magenta ink 


\section{b) Electrolyte formulation and electrochemical characterization}

Due to the low solubility of ECP-Magenta in water and in most organic solvents, the use of ion gel membranes (IGs), as electrolyte, seems to be very attractive. In our case the use of poly(vinylidenefluoride-co-hexafluoropropylene)/ionic liquid based ion gels is the best approach for building the electrochromic devices due to not only the chemical stability of the ECP-Magenta@ATO/TiO2 particles in the ion gel membrane but also the stability, chemical resistance and mechanical strength offer by it. Hence, a new approach based on using IGs and ECP-Magenta as electrolyte and electrochrom, respectively, is explored in other to design low power devices with high fatigue resistance properties.

Ionic conductivity of IGs. The physical and chemical properties of synthesized IGs facilitate the fabrication of EC devices by screen printing as well as a full construction of EC device in solid state. Conductivity of pure RTILs [EMIM][TFSI], [BMIM][TFSI], $[\mathrm{BMIM}]\left[\mathrm{BF}_{4}\right]$ and $[\mathrm{BMIM}]\left[\mathrm{PF}_{6}\right]$ as well as IGs prepared at different weight ratio of ILs mentioned above have previously been explored by EIS at room temperature using interdigitated electrodes. response of AC impedance of IGs using interdigitated electrodes with a simple equivalent circuit ${ }^{39}$. Here, conductivity of IGs has been determined comparing its AC impedance response at interdigitated gold microband electrodes ${ }^{40}$. The equivalent circuit consisted of a constant phase element (CPE) in series with a resistance, $R s$ representing the bulk electrolyte resistance, while the CPE represents the electrode/electrolyte interface. An additional CPE could be considered in parallel to Rs, related to the bulk electrolyte relaxation process $^{34}$, but this contribution was considered negligible in the experimental frequency range. The experimental and simulated data fits well indicating the validity of the proposed equivalent circuit (Figure 3 ). 


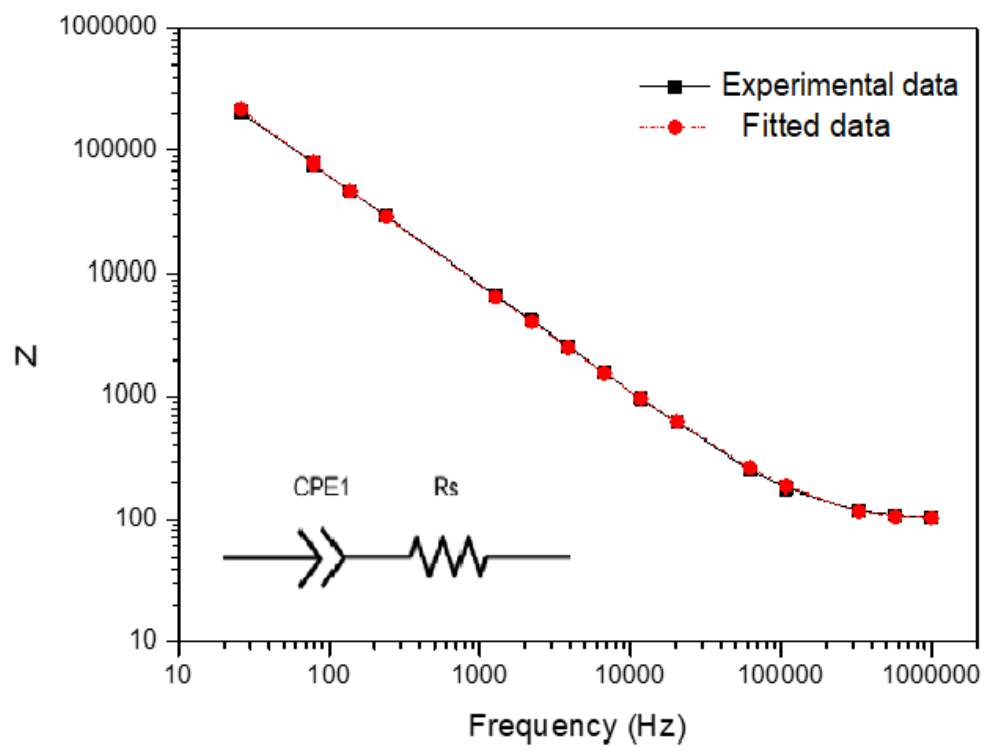

Figure 3. Bode plot. General behaviour for studies electrolytes. Square symbols correspond to experimental data of IG P(VDF-coHFP):[BMIM][TFSI] at a weight ratio of 1:5. Red circles corresponds to fitted data from the equivalent circuit.

The magnitude of the electrolyte resistance was estimated from the Bode plot at high AC frequencies, where the main impedance contribution corresponds to the electrolyte resistance, because $|\mathrm{Z}|$ does not depend on the frequency signal at high frequencies.

Results for each studied electrolyte are summarized in Table 1. When a RTIL is incorporated into the P(VDF-co-HFP) matrix, the conductivity of the resulting IGs gradually increase until they reach the ionic association point. Beyond this, conductivity decreases as more RTIL is added due to the saturation of ions at high concentrations. Nevertheless, there exists a compromise between their ionic conductivities and their rheological properties since low content of RTIL leads to a more crystalline electrolyte with low conductivity. When RTIL is added to the polymer the membrane becomes flexible and its conductivity increases. At higher amounts of RTIL, the resulting IG becomes less mechanically consistent.

For this reason, the IG composed by P(VDF-co-HFP) - [BMIM][TFSI] at a weight ratio of $1: 5$ is the one used for the following spectroelectrochemical study since it shows a sufficient ionic conductivity, transparency, flexibility, and the possibility to be cut and stick or even screen-printed. This formulation allows us to screen print an electrolyte layer, leading to a simple fabrication process. 
Electrochemical windows. IGs were explored by cyclic voltammetry to demonstrate that the electrolyte is electrochemically stable in the voltage window where many electrochromic polymers are switched. Figure 4 shows cyclic voltammograms of IGs containing ILs at a weight ratio of 1:5 and at a scan rate of $50 \mathrm{mV} / \mathrm{s}$. The electrochemical window of IGs spans from $-2 \mathrm{~V}$ to $+2 \mathrm{~V}$ vs SCE, bound by the reduction and oxidation of the RTIL anion and cation, respectively. The electrochemical window is wide enough to be used as electrolytes in the fabrication of ECDs. These results establish that the formulated IGs are electrochemically stable for this application, since the oxidation of ECP-Magenta occurs at $c a .0 .3 \mathrm{~V}$ vs $\mathrm{Ag} / \mathrm{AgCl}$.

Table 1. IGs formulation and conductivities.

\begin{tabular}{|c|c|c|}
\hline Sample & P(VDF-co-HFP) : IL weight ratio & Conductivity $(\mathrm{mS} / \mathrm{cm})$ \\
\hline [EMIM][TFSI] & - & 8,890 \\
\hline $\mathrm{P}(\mathrm{VDF}-$-co-HFP $)-[$ EMIM] $]$ TFSI] & $1: 1$ & 0,102 \\
\hline $\mathrm{P}(\mathrm{VDF}-$-co-HFP $)-[$ EMIM][TFSI] & $1: 3.5$ & 0,091 \\
\hline $\mathrm{P}(\mathrm{VDF}-$-co-HFP $)-[$ EMIM][TFSI] & $1: 5$ & 0,052 \\
\hline [BMIM][TFSI] & - & 3,900 \\
\hline $\mathrm{P}(\mathrm{VDF}-\mathrm{co}-\mathrm{HFP})-[\mathrm{BMIM}][\mathrm{TFSI}]$ & $1: 1$ & 0,056 \\
\hline $\mathrm{P}(\mathrm{VDF}-\mathrm{co}-\mathrm{HFP})-[\mathrm{BMIM}][\mathrm{TFSI}]$ & $1: 3.5$ & 0,085 \\
\hline $\mathrm{P}(\mathrm{VDF}-$-co-HFP $)-[$ BMIM] $[$ TFSI $]$ & $1: 5$ & 0,104 \\
\hline$[\mathrm{BMIM}]\left[\mathrm{BF}_{4}\right]$ & - & 3,700 \\
\hline $\mathrm{P}(\mathrm{VDF}-\mathrm{co}-\mathrm{HFP})-[\mathrm{BMIM}]\left[\mathrm{BF}_{4}\right]$ & $1: 1$ & 0,057 \\
\hline $\mathrm{P}(\mathrm{VDF}-\mathrm{co}-\mathrm{HFP})-[\mathrm{BMIM}]\left[\mathrm{BF}_{4}\right]$ & $1: 3.5$ & 0,051 \\
\hline $\mathrm{P}(\mathrm{VDF}-$-co-HFP $)$ - [BMIM $]\left[\mathrm{BF}_{4}\right]$ & $1: 5$ & 0,046 \\
\hline$[\mathrm{BMIM}]\left[\mathrm{PF}_{6}\right]$ & - & 2,200 \\
\hline $\mathrm{P}(\mathrm{VDF}-\mathrm{co}-\mathrm{HFP})-[\mathrm{BMIM}]\left[\mathrm{PF}_{6}\right]$ & $1: 1$ & 0,290 \\
\hline $\mathrm{P}(\mathrm{VDF}-\mathrm{co}-\mathrm{HFP})-[\mathrm{BMIM}]\left[\mathrm{PF}_{6}\right]$ & $1: 3.5$ & 0,136 \\
\hline $\mathrm{P}(\mathrm{VDF}-\mathrm{co}-\mathrm{HFP})-[\mathrm{BMIM}]\left[\mathrm{PF}_{6}\right]$ & $1: 5$ & 0,170 \\
\hline
\end{tabular}

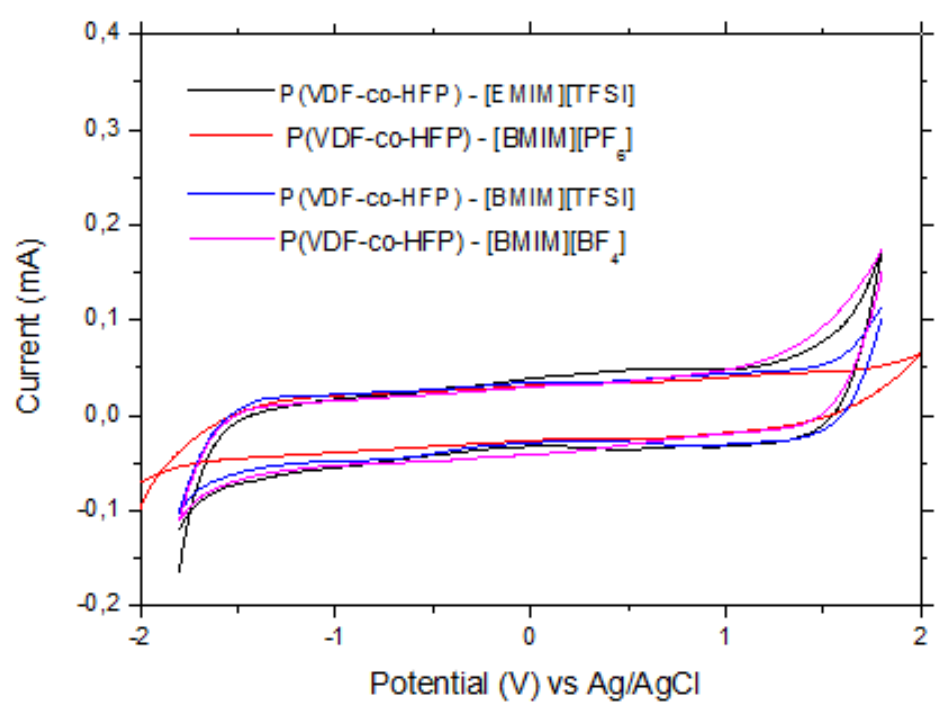

Figure 4. Cyclic Voltammograms of several IGs at $v=50 \mathrm{mV} / \mathrm{s}$. Scan Range: $0.00 \mathrm{~V} /-1.90 \mathrm{~V} / 1.90 \mathrm{~V} / 0.00$. 


\section{c) Electrochromic properties of ECP-Magenta ink using P(VDF-co-HFP) - [BMIM][TFSI] at a weight ratio of $1: 5$ as electrolyte}

Handmade screen-printed electrodes were used to explore the performance of the electrochromic ECP-Magenta paste/ink using IG electrolyte. Fabrication and characterization of handmade screen-printed electrodes has been previously reported. ${ }^{41}$ Electrochromic properties of formulated ECP-Magenta ink were explored using sample of $[\mathrm{BMIM}][\mathrm{TFSI}]$ as IG electrolyte at a weight ratio of 1:5 (P(VDF-coHFP):[BMIM][TFSI]) since it has shown one of the highest conductivities as well as good transparency and flexibility. Similar results were found for IG-[EMIM][TFSI], suggesting the possibility of using it as electrolyte indistinctly. For this study, the resulting ECP-Magenta ink was stenciled covering the working electrode, and the IG electrolyte was cut and placed covering the counter and working electrodes (Figure 5).
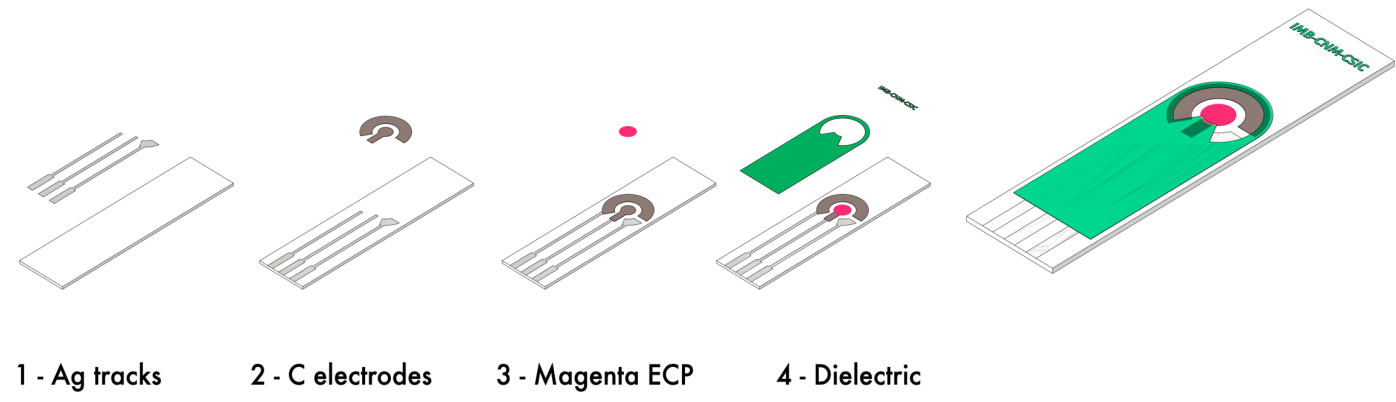

1 - Ag tracks

2 - C electrodes

3 - Magenta ECP

4 - Dielectric

Figure 5. Handmade electrode fabrication by screen-printing

Cyclic Voltammetry Experiments. CV was used to determinate the redox potential at which ECP-Magenta ink switches between its two coloured states. Figure 6 shows CV curves of ECP-Magenta ink using IG-[BMIM][TFSI] as electrolyte at a scan rate of $50 \mathrm{mV} / \mathrm{s}$. Hence, for all the experiments scan range used was from $-0.30 \mathrm{~V}$ to $0.60 \mathrm{~V}$ vs $\mathrm{Ag} / \mathrm{AgCl}$, since ECP-Magenta shows a single reversible peak $\left(E_{p a}=0.30 \mathrm{~V}\right.$ and $E_{p c}=0.20 \mathrm{~V}$ vs $\mathrm{Ag} / \mathrm{AgCl})$. Note that the electrochemical oxidation potential of ECP-Magenta ink in film using IG-[BMIM][TFSI] electrolyte is slightly shifted to $0.3 \mathrm{~V}$ due to its electronrich character. Figure $6 \mathrm{~b}$ shows a linear relationship between the anodic peak current density and the scan rate from $5 \mathrm{mV} / \mathrm{s}$ to $200 \mathrm{mV} / \mathrm{s}$. This is consistent with the fact that the electroactive compound is fixed on the electrode surface, unable to diffuse, the Randles $\&$ Sevčik equation for diffusion-controlled systems is no longer valid. Thus, a modified 
equation for describing thin-film cyclic voltammetry processes is used. The relation between peak current and scan rate is given by equation $1:{ }^{42}$

$$
I_{p}=n^{2} F^{2} \Gamma v / 4 R T
$$

where $\Gamma$ is the total amount of active species initially present at the electrode surface. According to this equation, peak currents showing a linear dependence between peak current density and scan rate prove the formation of well adhered polymer films and nondiffusion controlled reversible redox processes in this scan rate range.
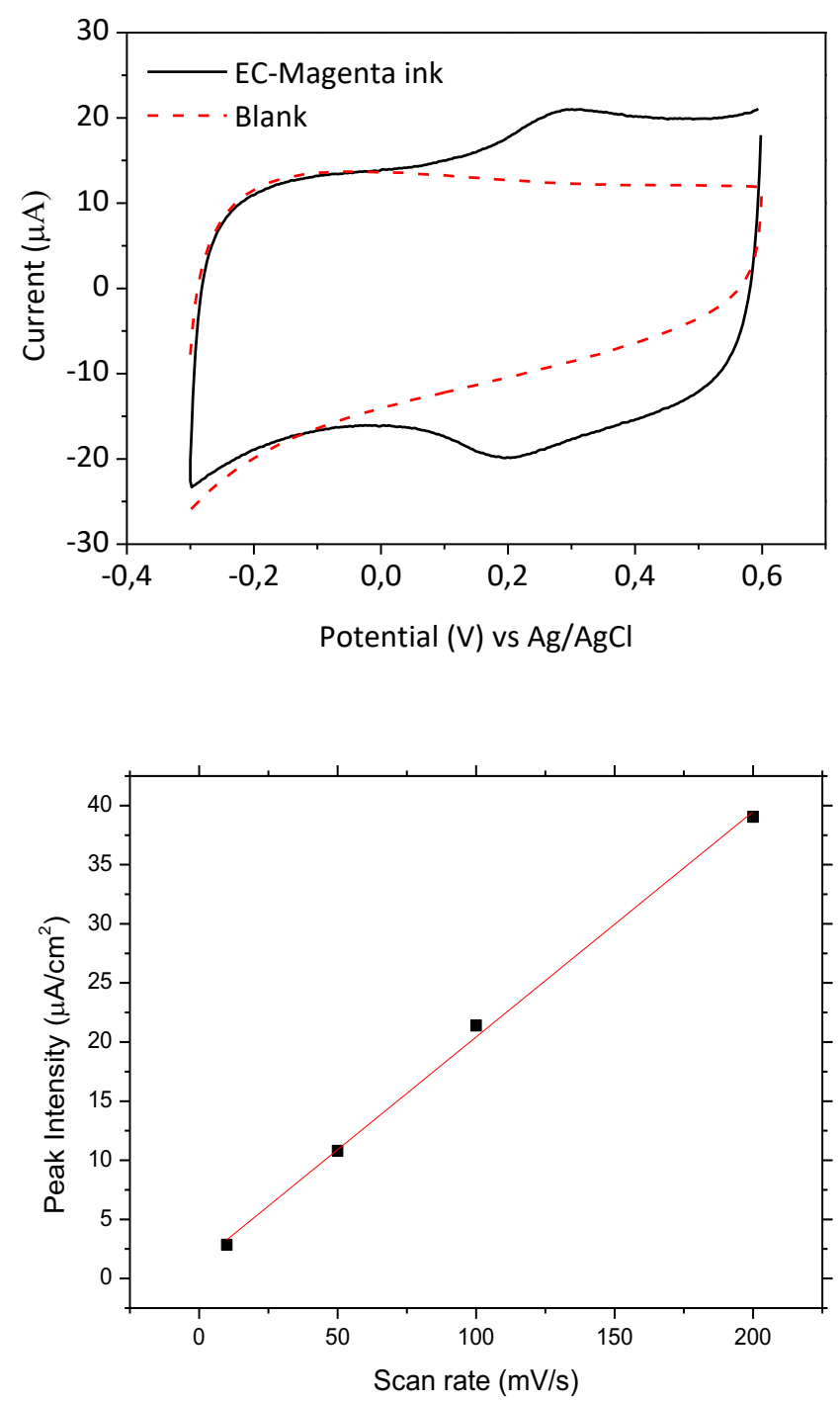

Figure 6. Fig a) Cyclic Voltammograms of EC-Magenta paste/ink using IG-[BMIM][TFSI] as electrolyte (solid black line) and blank (red dashed line) b) Current Intensity of anodic peaks as a function of the scan rate 


\section{Spectroelectrochemical study of EC-Magenta ink using p(VDF-co-HFP)-}

[BMIM][TFSI] at a weight ratio of 1:5 as electrolyte. ECP-Magenta ink presents two stable states with different electrooptical properties resulting from the reversible redox reaction (Figure 7). The UV-vis spectra of neutral ECP-magenta ink shows an intense absorption band at $\lambda_{\max }=528 \mathrm{~nm}$ (Figure 8 ), which is in good agreement with previous reported data. ${ }^{15}$ This strong absorption in the visible range originates from the polymer's $\pi-\pi^{*}$ transition. Electrochemical oxidation of ECP-Magenta leads to the formation of charged states along the backbone (cation radical and dication), where light absorption is transitioned to longer wavelengths, outside of the visible region, with a concurrent loss of absorption from the $\pi-\pi^{*}$ transition. The minimum oxidation potential, $E_{p a}$, at which the EC-Magenta is reversibly oxidized, was determined from the voltabsortogram shown in Figure 9. Voltabsortograms show the transient reflectance change at a specific wavelength in response to a voltage sweep. From the voltabsortogram the maximum change in reflectance matches the anodic peak from the $\mathrm{CV}$ at $0.3 \mathrm{~V}$ vs $\mathrm{Ag} / \mathrm{AgCl}$. To evaluate the contrast and ensure complete conversion between the two states, the film was switched between $0.40 \mathrm{~V}$ vs $\mathrm{Ag} / \mathrm{AgCl}$ (colorless) and $0.1 \mathrm{~V}$ vs $\mathrm{Ag} / \mathrm{AgCl}$ (coloured). Color contrast was estimated by the difference in $\%$ between the reflectance value at $\lambda_{\max }$ of its neutral and oxidized state which in this case was $60 \%$.

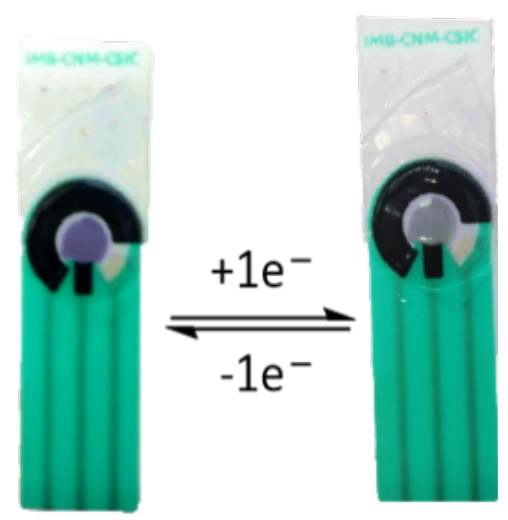

Figure 7. Performance of ECP-Magenta using state using IG-[BMIM][TFSI] as electrolyte before (left) and after (right) applying $0.4 \mathrm{~V}$ 


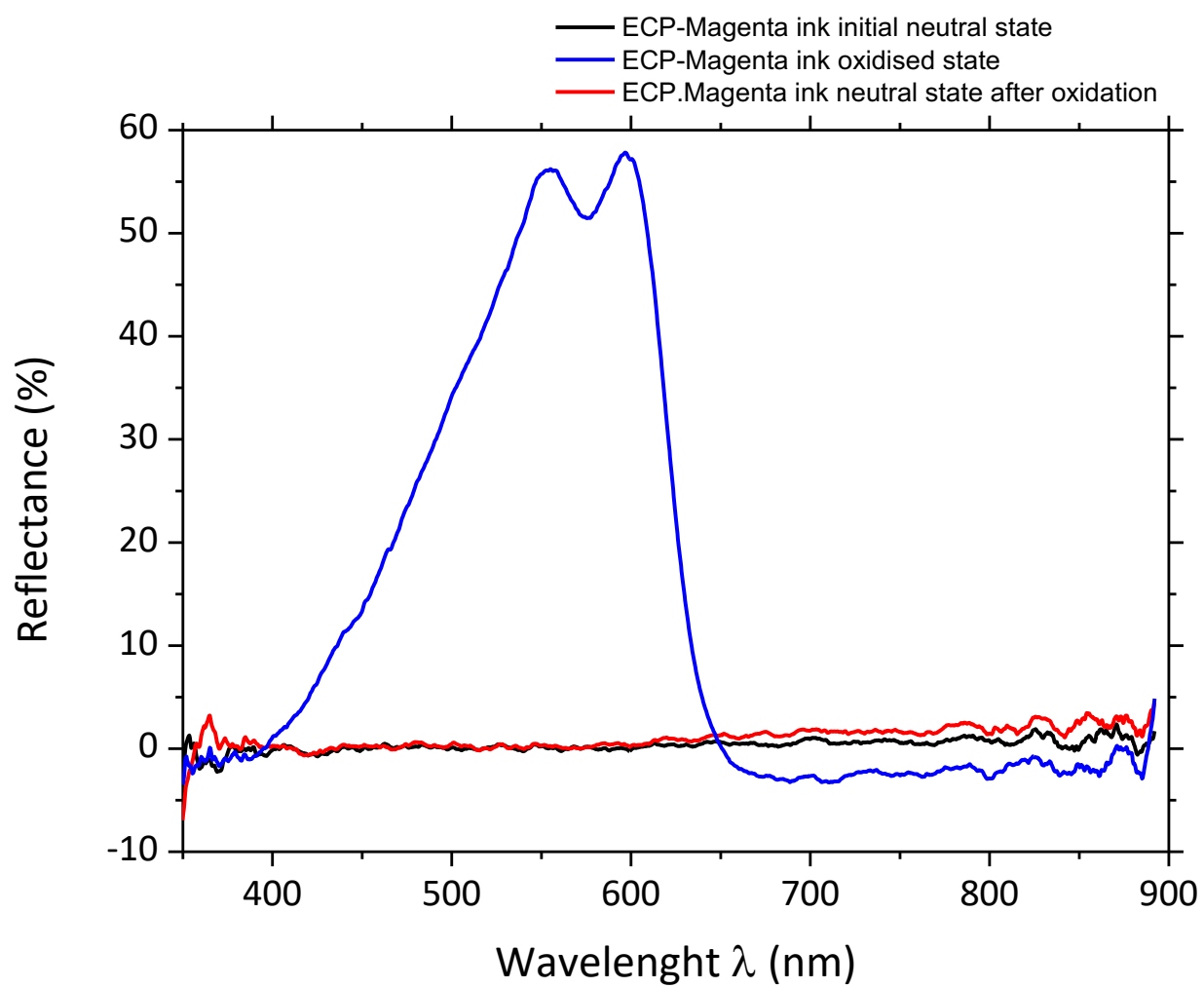

Figure 8. UV-vis reflectance spectra of EC-Magenta paste/ink in its neutral and oxidized state using IG-[BMIM][TFSI] as electrolyte

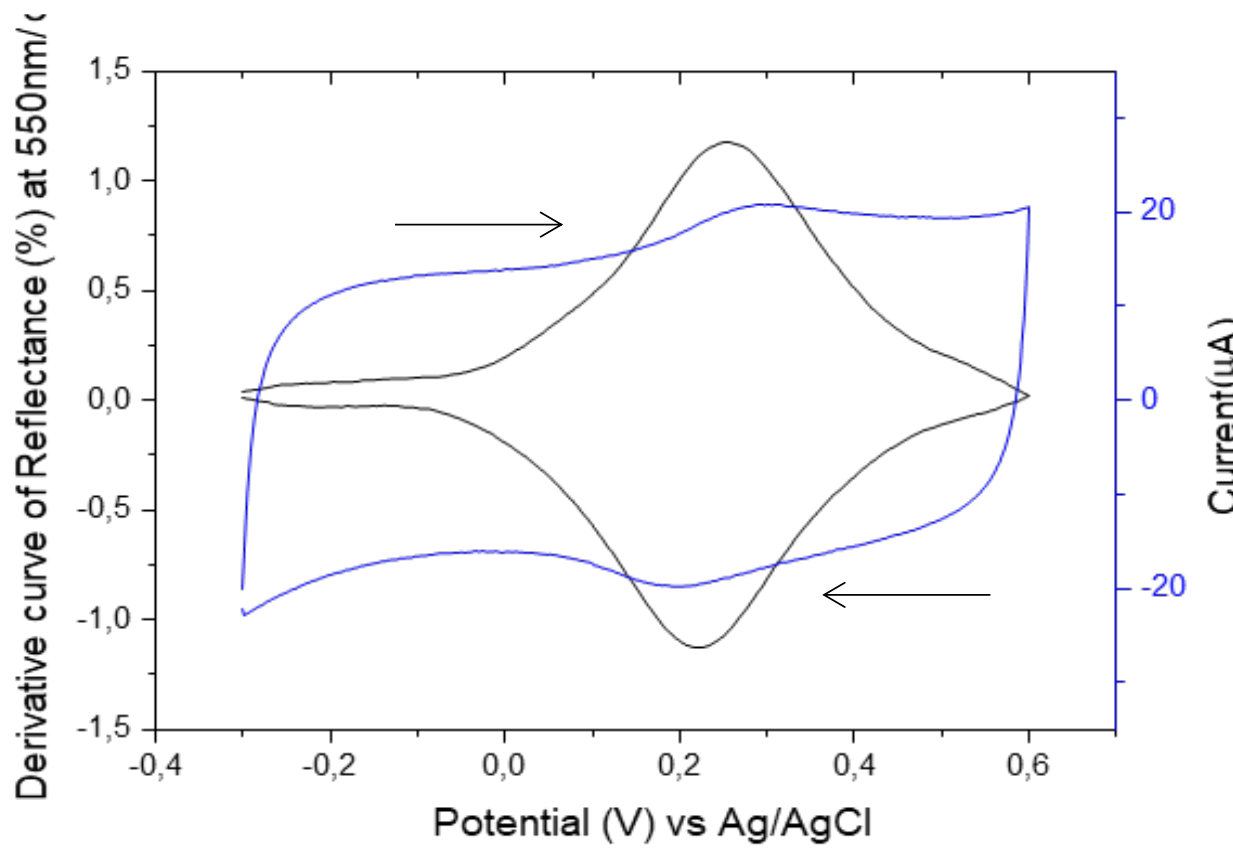

Figure 9. Voltoabsortogram and overlayed cyclic voltammogram of ECP-Magenta ink using IG-[BMIM][TFSI] as electrolyte 
The cycling stability (fatigue resistance) of ECP-Magenta ink performed using [BMIM][TFSI] IG as electrolyte, was evaluated by chronoamperometry (CA) measurements and recording its reflectance UV-vis spectra at $550 \mathrm{~nm}$ in situ. The electrochromic parameters are depicted in Table 2. Switching colour between the two ECP-Magenta states were explored by applying $0.4 \mathrm{~V}$ and $0.1 \mathrm{~V}$ for $5 \mathrm{~s}$ at each step. After switching 500 cycles colour contrast decreased approximately by $20 \%$. The aim is to select the minimum potential at which the color change occurs to ensure a final device that could work at a potential below $1 \mathrm{~V}$ or less. For this reason, the contrast decay may be related to the narrow voltage window we applied. The response time is defined as the time required for $90 \%$ reflectance change in the bleaching process $\left(\tau_{\mathrm{b}}\right)$ and colouring process $\left(\tau_{\mathrm{c}}\right)$. The response time is about $2 \mathrm{~s}$ and there is no significant change on its value after and before 500 cycles; (Figure 10) which meets the requirement for most electrochromic devices $(0.1 \mathrm{~s}-10 \mathrm{~s})$.

Coloration efficiency (CE) is defined as the change in optical density $(\triangle \mathrm{OD})$ induced by unit charge density. $\mathrm{CE}$ is calculated from the equations 2 and 3, where $T c$ and $T b$ are the transmittance or reflection values of the colored and bleached states, respectively.

$$
\begin{gathered}
\mathrm{CE}=\frac{\Delta \mathrm{OD}}{\mathrm{Q}} \\
\Delta \mathrm{OD}=\log \left(\mathrm{T}_{\mathrm{c}} / \mathrm{T}_{\mathrm{b}}\right)
\end{gathered}
$$

The calculated CE values of EC-Magenta using IG-[BMIM][TFSI] as electrolyte is 496 $\mathrm{cm}^{2} / \mathrm{C}$ which is in agreement with other studies and indicates that little charge is needed to produce a measurable color change. ${ }^{43}$ These results suggest that these new materials perform well and are promising candidates for application in flexible ECD. 


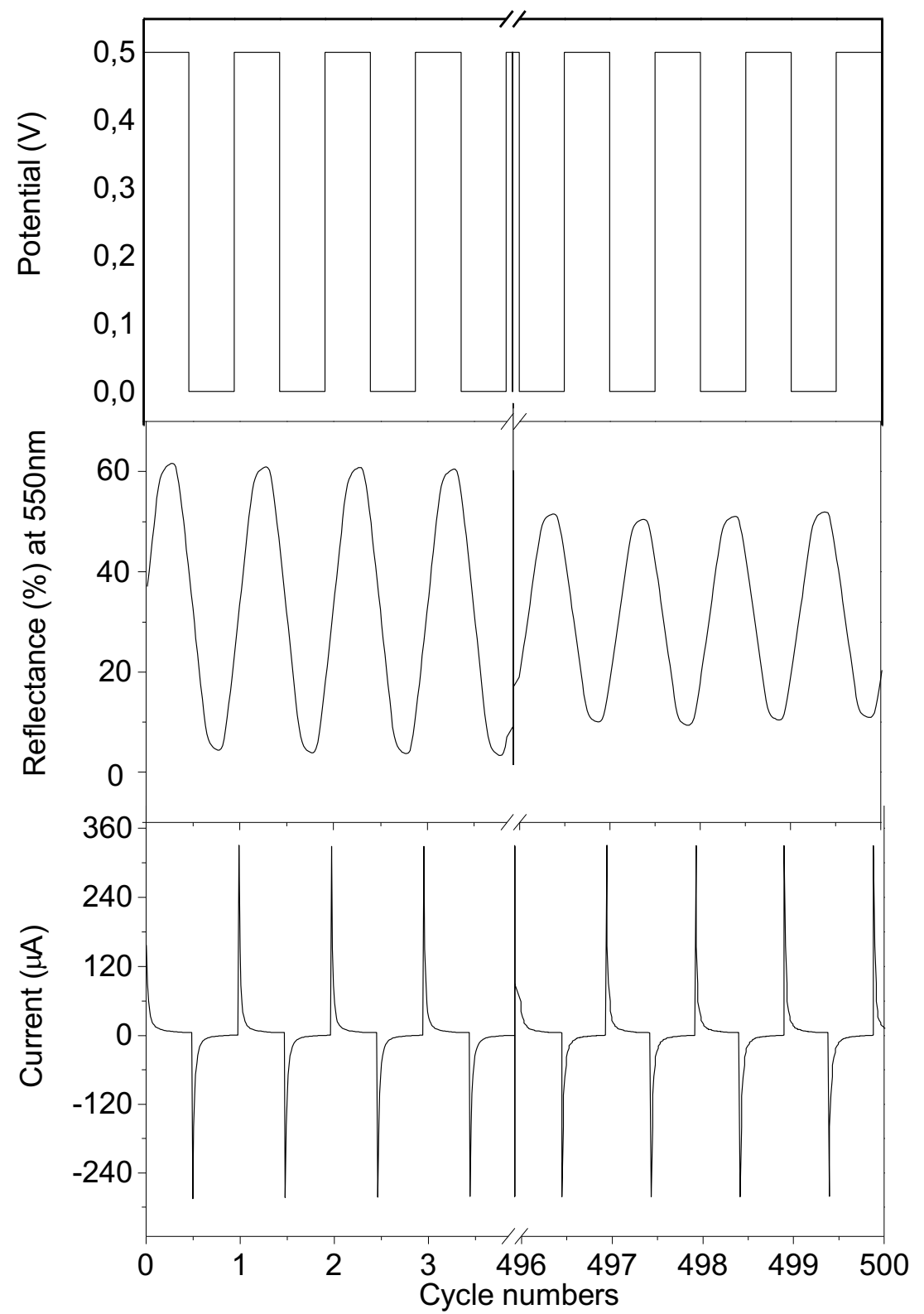

Figure 10. Applied potential, chronoamperogram, and transmittance of EC-Magenta ink using IG-[BMIM][TFSI] as electrolyte.

Table 2. Electrochromic parameters of EC-Magenta ink using IG[BMIM][TFSI] as electrolyte.

\begin{tabular}{cccccc}
\hline Cycles & $\Delta \mathrm{T}(\%)$ & $\mathbf{T}_{\mathbf{c}}(\mathbf{s})$ & $\mathbf{T b}_{\mathbf{b}}(\mathbf{s})$ & $\Delta \mathrm{OD}$ & $\begin{array}{c}\mathbf{C E} \\
\left(\mathbf{c m}^{2} / \mathbf{C}\right)\end{array}$ \\
\hline $1-4$ & $60 \%$ & 2,1 & 2,2 & 0,190 & 496 \\
$496-500$ & $40 \%$ & 2,04 & 2,04 & 0,13 & -
\end{tabular}




\section{Conclusions}

A novel screen-printable ink based on ECP-Magenta has been successfully formulated using ECP-Magenta, ATO/TiO 2 nanoparticles, and a $\mathrm{P}(\mathrm{VDF}-\mathrm{co}-\mathrm{HFP})$ binder. The ink films showed significant colour change at low potentials $(0.3 \mathrm{~V}$ vs $\mathrm{Ag} / \mathrm{AgCl})$ in comparison with other electrochromic composite films or ink formulation. Besides, this new ECP-Magenta ink exhibits higher optical contrast values and coloration efficiency. Response time for bleaching and colouring is $\sim 2 \mathrm{~s}$ which can be improved by optimizing the thickness of the film. Note that the formulation of the electrochromic ink is compatible with the use of "eco-friendly" flexible electrolytes, such as RTIL-IGs. Besides, this strategy will enable the formulation of further inks using different organic electrochromic compounds. All these features, specially its low potential at which the colour change occurs, enable to use this material in the fabrication of smart devices, such as flexible displays or sensors. In the case of sensors, thanks to this formulation, they can be totally manufactured using screen-printing technologies. Thus, the use of this low-cost, easy and reproducible methodology for a next generation of devices based on this material is potentially available.

\section{Experimental Section}

\section{Materials}

Poly(3,4-propylenedioxythiophene)bis(ethylhexyloxy) or EC-Magenta polymer of $15 \mathrm{kDa}$, was used as the EC material on the active layer and kindly provided by The Reynolds Research Group. EC-Magenta was synthesized according to previously reported procedure ${ }^{14}$. Toluene (99\%, Sigma-Aldrich) was used to dissolve EC-Magenta. Poly(vinylidenefluoride-co-hexafluoropropylene), $\quad$ P(VDF-co-HFP), with $\mathrm{Mw}=400000 \mathrm{~g} / \mathrm{mol}$ was purchased from Sigma-Aldrich and used as received. Ionic liquids, [BMIM][TFSI], [EMIM][TFSI], were purchased from Solvionic and stored under dried conditions. Antimony-tin oxide particles (ZELEC 1610-S) were kindly provided by Milliken Chemical Company. Zelec materials by Milliken provide cost-effective, staticdissipative performance for coatings and polymers. They are non-volatile, non-corrosive, and resistant to heat, chemicals and humidity. Zelec enhances quality and durability by imparting resistivity throughout the lifetime of coatings, paints, and security inks and 
electronics products. ITO nanoparticles were purchased from Alfa Aesar (ITO Nanotek, ref. 44927).

Screen printed electrodes were homemade and used for the spectroelectrochemical and electrochemical characterization. Carbon ink (C2030519P4) was used for working and counter electrodes and silver/silver chloride (C61003P7) screen-printing paste for reference electrode (Gwent Electronic Materials Ltd., UK)

\section{Preparation of EC-Magenta ink}

$6 \mathrm{~mL}$ of a solution of EC-magenta polymer in dichloromethane at $30 \mathrm{mg} / \mathrm{mL}$ concentration was sonicated for 15 minutes with $1 \mathrm{~g}$ ATO/SiO2-NP's. Remaining dichloromethane was evaporated at room temperature and the resulting conductive powders were manually ground using a mortar and pestle. A resin binder is prepared by mixing $\mathrm{P}(\mathrm{VDF}-\mathrm{co}$-HFP) at $15 \%$ wt. in dimethylpropilurea (DMPU) and heated at $80^{\circ} \mathrm{C}$. Eventually, the dryed particles were mixed and dispersed in a resin binder in a pigment-to-binder weight ratio of 1:5. After throrough mixing, a smooth paste is obtained.

\section{Preparation of Ion Gels (IGs)}

All the chemicals used for the preparation of Ion Gels (IGs) were dry. A desired amount of and P(VDF-co-HFP) polymer was dissolved in anhydrous acetone under stirring at $50^{\circ} \mathrm{C}$ until a homogeneous solution was obtained. Ionic Liquid (IL) was added then at different weight ratios on the previous solution (1:1/ 1:3 / 1:5; P(VDF-co-HFP):IL) and stirred again for $1 \mathrm{~h}$. The resulting viscous solution was transferred to ceramic evaporating dish and was left at room temperature for $24 \mathrm{~h}$ until the solvent was completely evaporated. Eventually, a transparent, flexible and elastic thin film was obtained that could be cut with any shape and stick on a substrate. Note that the thickness of the film is c.a. $10 \mu \mathrm{m}$, hence it is able to work in transmittance mode using a reflectance setup.

\section{Instrumentation.}

Electrochemical Impedance Spectroscopy (EIS) experiments were performed at room temperature using Solartron 1287 potentiostat/galvanostat interfaced to a frequency response analyser (Solartron 1260). EIS was measured over the frequency range from 1 $\mathrm{MHz}$ to $0.1 \mathrm{~Hz}$ at a potentiostatic signal amplitude of $15 \mathrm{mV}$. Interdigitated electrodes of 
Au with 54 x 2 bands $10 \mu \mathrm{m}$ of width and $1500 \mu \mathrm{m}$ of length were used for impedance measurements.

Electrochemical characterization of EC-Magenta and EC-Magenta paste, potentiostat VSP100 model and EC-Lab V9.51 software was used. Absorbance spectroelectrochemical measurements, potentiostat was coupled to Hamamatsu spectrophotometer L10290 model. DRP-SPELEC1050 model was used in further spectroelectrochemical studies enabling recording reflectance and transmittance spectra of opaque screen-printed electrodes.

Morphology and chemical analysis of EC-Magenta paste was studied with Auriga-40 (Carl Zeiss) Scanning Electron Microscopy (SEM) carried out by CNM Inspection Laboratory.

\section{Acknowledgements}

GG and SS acknowledge the Spanish Ministry for Education, Culture and Sports for financial support through CTQ2015 65439-R from 688 the MINECO/FEDER. SS and MA are supported by FEDER funds managed by the Catalan Secretary of Universities and Research through project PROD-0000114 (Enterprise and Knowledge, Industry Department, Generalitat de Catalunya). JdC gratefully acknowledges financial support through a 2016 BBVA Foundation Grant for Researchers and Cultural Creators. The authors are grateful to Milliken for providing the electroconductive powders featured in this work. Finally, the authors are pleased to acknowledge the Reynolds Group (Drs. Anna M. Österholm, Eric Shen, and John R. Reynolds) of Georgia Institute of Technology, Atlanta (USA) for generously providing the ECP-Magenta polymer, and for their continued support, availability, helpful discussions and technical advice.

\section{References}

(1) Mortimer, R. J. Annu. Rev. Mater. 2011, 41 (1), 241-268.

(2) Lampert, C. M. Sol. Energy Mater. Sol. Cells 2003, 76 (4), 489-499.

(3) Granqvist, C. G. Thin Solid Films 2014, 564, 1-38. 
(4) Azens, A.; Granqvist, C. G. J. Solid State Electrochem. 2003, 7 (2), 64-68.

(5) Chandrasekhar, P.; Zay, B. J.; Cai, C.; Chai, Y.; Lawrence, D. J. Appl. Polym. Sci. 2014, 131 (22), 1-21.

(6) Mortimer, R. J.; Rosseinsky, D. R.; Monk, P. M. S. Electrochromic Mater. Devices 2015, 77, 1-638.

(7) V. Beni, D. Nilsson, P. Arven, P. Norberg, G. Gustafsson, and A. P. F. T. ECS J. Solid State Sci. Technol. 2015, 4 (10), S3001-S3005.

(8) P. A. Ersman, J. Kawahara, M. B. Org. Electron. physics, Mater. Appl. 2013, 14 (12), 3371-3378.

(9) A. Malti, R. Brooke, X. Liu, D. Zhao, P. Andersson Ersman, M. Fahlman, M. P. Jonsson, M. Berggren, and X. C. J. Mater. Chem. C 2016, 4 (41), 9680-9686.

(10) Dyer, A. L.; Österholm, A. M.; Shen, D. E.; Johnson, K. E.; Reynolds, J. R. Electrochromic Mater. Devices 2015, 113-184.

(11) Elschner, A. PEDOT; 2011.

(12) Remmele, J.; Shen, D. E.; Mustonen, T.; Fruehauf, N. ACS Appl. Mater. Interfaces 2015, 7 (22), 12001-12008.

(13) Dyer, A. L.; Thompson, E. J.; Reynolds, J. R. ACS Appl. Mater. Interfaces 2011, $3(6), 1787-1795$.

(14) Reeves, B. D.; Grenier, C. R. G.; Argun, A. A.; Cirpan, A.; McCarley, T. D.; Reynolds, J. R. Macromolecules 2004, 37 (20), 7559-7569.

(15) Eric Shen, D.; Österholm, A. M.; Reynolds, J. R. J. Mater. Chem. C 2015, 3 (37), 9715-9725.

(16) Sondergaard, R. R.; Hösel, M.; Jørgensen, M.; Krebs, F. C. J. Polym. Sci. Part B Polym. Phys. 2013, 51 (2), 132-136.

(17) Padilla, J.; Österholm, A. M.; Dyer, A. L.; Reynolds, J. R. Sol. Energy Mater. Sol. Cells 2015, 140, 54-60.

(18) Österholm, A. M.; Shen, D. E.; Gottfried, D. S.; Reynolds, J. R. Adv. Mater. Technol. 2016, 1 (4). 
(19) Dyer, A. L.; Craig, M. R.; Babiarz, J. E.; Kiyak, K.; Reynolds, J. R. Macromolecules 2010, 43 (10), 4460-4467.

(20) Yin, Y.; Li, W.; Zeng, X.; Xu, P.; Murtaza, I.; Guo, Y.; Liu, Y.; Li, T.; Cao, J.; He, Y.; Meng, H. Macromolecules 2018, 51 (19), 7853-7862.

(21) Matyba, P.; Yamaguchi, H.; Eda, G.; Chhowalla, M.; Edman, L.; Robinson, N. D. ACS Nano 2010, 4 (2), 637-642.

(22) Ju, S. H.; Ju, B. K.; Choi, J. H.; Kim, Y. M.; Park, Y. W.; Paek, K. K.; Lee, J. W.; Yang, J. W.; Huh, J. W.; Lee, J. W. J. Appl. Phys. 2008, 103 (4), 44502.

(23) Birnstock, J.; Blässing, J.; Hunze, A.; Scheffel, M.; Stößel, M.; Heuser, K.; Wittmann, G.; Wörle, J.; Winnacker, A. Appl. Phys. Lett. 2001, 78 (24), 39053907.

(24) Krebs, F. C. Sol. Energy Mater. Sol. Cells 2009, 93 (4), 394-412.

(25) Coleman, J. P.; Lynch, A. T.; Madhukar, P.; Wagenknecht, J. H. Sol. Energy Mater. Sol. Cells 1999, 56 (3-4), 375-394.

(26) Fellow-, H. 1969, 56 (9), 4248-4250.

(27) Liu, J.; Coleman, J. P. Mater. Sci. Eng. A 2000, 286 (1), 144-148.

(28) Pellitero, M. A.; Guimerà, A.; Kitsara, M.; Villa, R.; Rubio, C.; Lakard, B.; Doche, M.-L.; Hihn, J.-Y.; Javier del Campo, F. Chem. Sci. 2017, 1995-2002.

(29) Pellitero, M. A.; Fremeau, J.; Villa, R.; Guirado, G.; Lakard, B.; Hihn, J.-Y.; del Campo, F. J. Sensors Actuators B Chem. 2019.

(30) Pellitero, M. A.; Colina, Á.; Villa, R.; del Campo, F. J. Electrochem. commun. 2018, 93, 123-127.

(31) Zhong, C.; Deng, Y.; Hu, W.; Qiao, J.; Zhang, L.; Zhang, J. Chem. Soc. Rev. 2015, 44 (21), 7484-7539.

(32) Alamer, F. A.; Otley, M. T.; Zhu, Y.; Kumar, A.; Sotzing, G. A. Sol. Energy Mater. Sol. Cells 2015, 132, 131-135.

(33) Lodge, T. P.; Ueki, T. Acc. Chem. Res. 2016, 49 (10), 2107-2114.

(34) Armstrong, R. D. J. Electroanal. Chem. 1974, 52 (3), 413-419. 
(35) Singh, V. K.; Singh, R. K. J. Mater. Chem. C 2015, 3 (iii), 7305-7318.

(36) Shalu; Singh, V. K.; Singh, R. K. J. Mater. Chem. C 2015, 3 (28), 7305-7318.

(37) Tang, Z.; Qi, L.; Gao, G. Polym. Adv. Technol. 2010, 21 (3), 153-157.

(38) Dong, B.; Zheng, L.; Xu, J.; Liu, H.; Pu, S. Polymer (Guildf). 2007, 48 (19), $5548-5555$.

(39) Laczka, O.; Baldrich, E.; Muñoz, F. X.; Del Campo, F. J. Anal. Chem. 2008, 80 (19), 7239-7247.

(40) O. Laczka, E. Baldrich, F. X. Muñoz, and F. J. del C. Anal. Chem. 2008, 80 (19), $7239-7247$.

(41) Randviir, E. P.; Brownson, D. A. C.; Metters, J. P.; Kadara, R. O.; Banks, C. E. Phys. Chem. Chem. Phys. 2014, 16 (10), 4598-4611.

(42) A. J. Bard and L. R. Faulkner. Electrochemical Methods: Fundamentals and Applications, 2nd ed.; New York, 2001.

(43) Zhang, S.; Sun, G.; He, Y.; Fu, R.; Gu, Y.; Chen, S. ACS Appl. Mater. Interfaces 2017, 9 (19), 16426-16434. 
Entry for the Table of Contents

\section{ARTICLE}

Designing polymer inks and electrolytes for screen-printable electrochromic devices
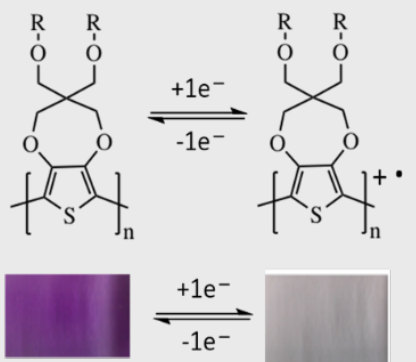

Neutral state

Colored

$$
\underset{-1 \mathrm{e}^{-}}{\stackrel{+1 \mathrm{e}^{-}}{\rightleftharpoons}}
$$

Sara Santiago, Miguel Aller, F. Javier del Campo*, and Gonzalo Guirado*

Page No. - Page No.

Title 